\title{
Artificial penile nodules and secondary syphilis
}

\author{
P Wolf, H Kerl
}

\begin{abstract}
A patient with artificial penile nodules and ulcerative plaques on the penis is described. Clinical course, histology and serological examination revealed a diagnosis of secondary syphilis. The differential diagnosis of the ulcerative genital lesions in the presence of artificial penile nodules is discussed.
\end{abstract}

\section{Case report}

A 25 year old formerly imprisoned Roumanian was admitted because of genital skin lesions of a few weeks duration. Clinical examination revealed a hypertrophic inflamed inner prepuce with ulcerated plaques (fig 1). Several hard, round subcutaneous penile nodules were also noted. The nodules measured about $1 \mathrm{~cm}$ in diameter. Four nodules were located symmetrically on the shaft of the penis (fig 1 ). These were non-tender and freely movable. The overlying skin and surrounding area were normal. The other two nodules were adherent and directly situated under the diseased prepuce (fig 1). The inguinal lymph nodes were enlarged bilaterally. The patient stated that all nodules had been produced by the implantation of spheres consisting of selfpolished material of a tooth brush. This procedure had been done two years before by a fellow-prisoner in Roumania.

A skin biopsy of the diseased prepuce (fig 2) revealed histologically psoriasiform hyperplasia of the epidermis and a superficial and deep mixedinflammatory cell infiltrate of lymphocytes, histiocytes and many plasma cells around telangiectatic vessels. Focally, the infiltrate showed a band-like pattern. Warthin-Starry staining did not disclose spirochetes. A diagnosis of secondary syphilis was made.

Dark-field microscopic examination of a smear from the inner prepuce was negative for Treponema pallidum. Serological tests for syphilis were as follows: VDRL 1:16 reactive; TPHA 1:5120 reactive; FTA-ABS ++ reactive; IgM-SPHA negative. On further questioning, the patient admit-

Department of Dermatology, University of Graz, Auenbruggerplatz 8, 8036-Graz, Austria P Wolf, H Kerl ted a possible infection after a sexual intercourse with a prostitute three months previously. A short treatment with tetracycline given orally was stated to have been applied two weeks prior to the admission.

Based on the clinical, histological and serological findings a diagnosis of secondary syphilis was made. Treatment with benzathine penicillin $G 2.4$ million units IM once a week for three successive weeks was administered. After three weeks a considerable clinical improvement could be noted, and after six weeks the lesions on the prepuce had resolved without any residual clinical sign. The enlarged inguinal lymph nodes had undergone involution. After three months the serological tests for syphilis

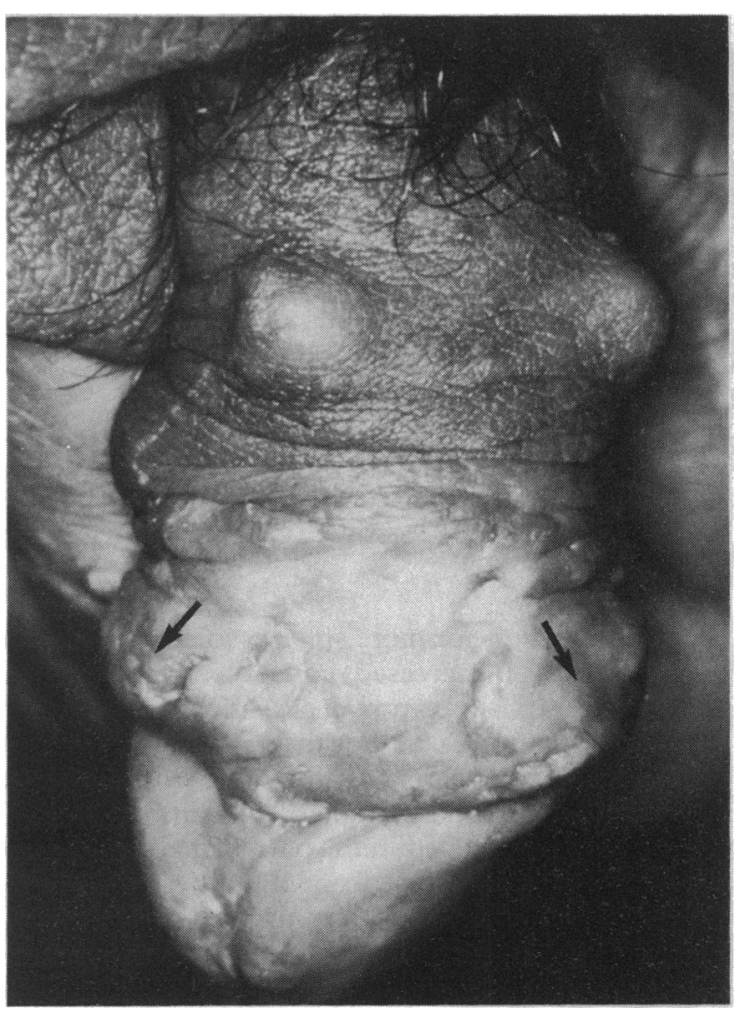

Figure 1 Artificial penile nodules and secondary syphilis. The inner prepuce is inflamed and thickened, showing ulcerated plaques. Two artificial penile nodules (arrows) were found under the diseased prepuce. Note three other nodules on the shaft of the penis. 

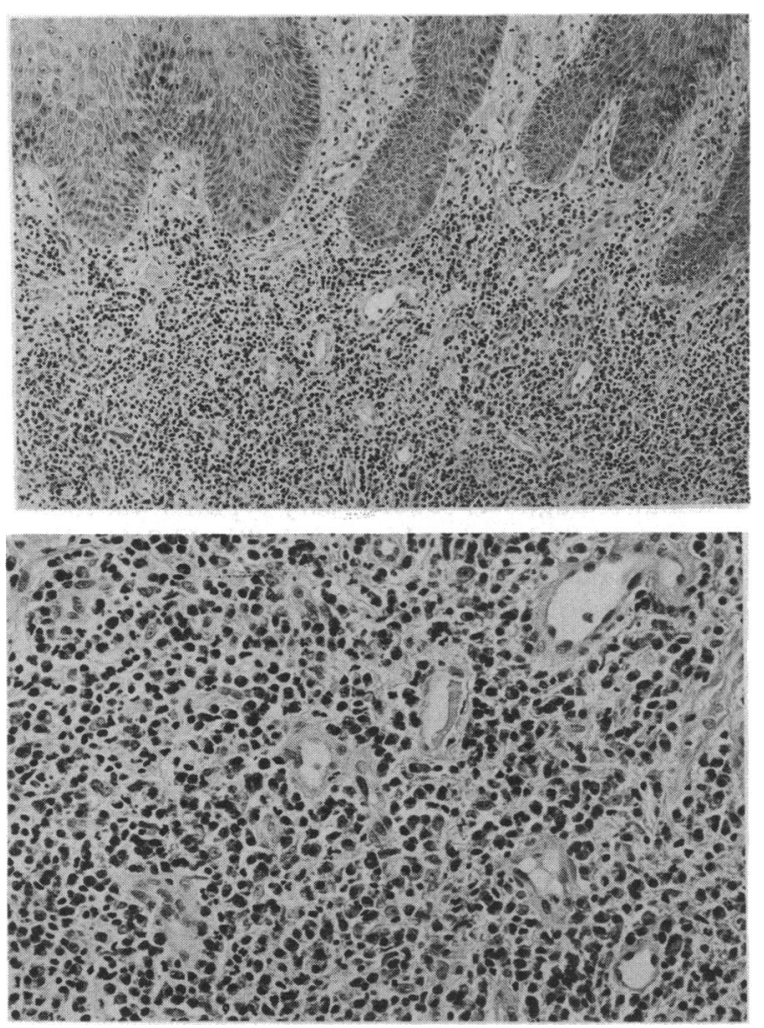

Figure 2 Artificial penile nodules and secondary syphilis. Skin biopsy specimen of the diseased prepuce.

(a) Psoriasiform hyperplasia of the epidermis and a bandlike mixed-inflammatory cell infiltrate ( $H$ and $E, \times 100)$. (b) Higher magnification of fig $2 a$. Mixed-inflammatory cell infiltrate of lymphocytes, histiocytes and many plasma cells around telangiectatic vessels ( $H$ and $E, \times 250$ ).

showed distinctly reduced titres (VDRL 1:2; TPHA 1:320; FTA-ABS + reactive; IgM-SPHA negative).

\section{Discussion}

Implanting of one or more spheres into the penis for the purpose of increased coital excitation of the sexual partner is a common procedure in Thailand and other countries of South-east Asia. ${ }^{1-5}$ Besides other penile artifacts as illustrated in fig 3 the implantation of spheres, called "Persimbraon", has been already described in the native race of Battas of Sumatra in the literature from $1894 .^{6}$

At present, the spheres are usually implanted by the individual himself or with the help of a nonmedical person. Any part of the skin of the penis may be split, but the dorsum is the most common site, after which the spheres are inserted. ${ }^{1}$ Numerous spheres may be implanted into the penis by this method. The wounds usually heal spontaneously without complications.

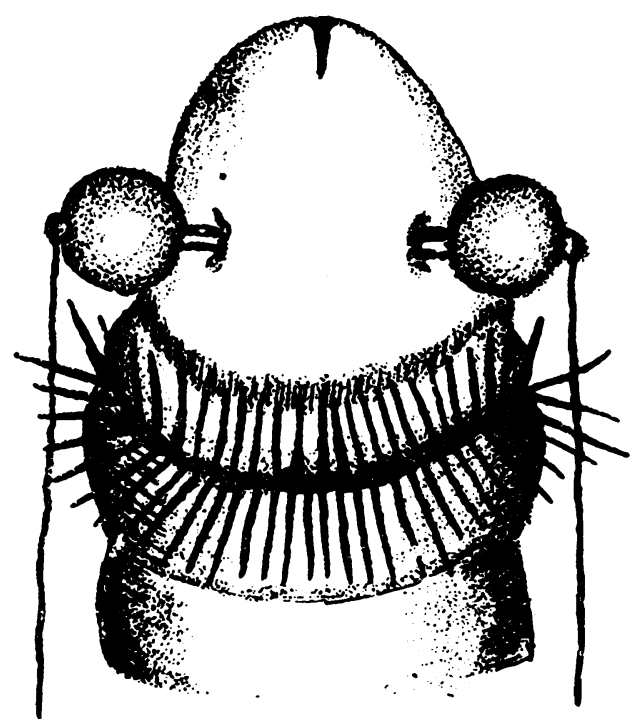

Figure 3 Penile artifacts in natives of South-east Asia. Socalled "Kambi" of Alfuros in North-Celebes. (Adapted from Hovorka, 1894, Ref. 6.)

Still the most common substance used to make the spheres is derived from the bottom of glass containers of Tancho pomade, a brand of Japanese hair pomade widely used in South-east Asia. The artificial penile nodules produced by using spheres of this rather inert type of glass are reported under the name of "Tancho's nodules". ${ }^{2}$ Besides glass beads, other materials such as pearls, jewels, bullets, paddies oras in our case-spheres from hard plastic are employed to produce artificial penile nodules. ${ }^{3}$ Except for secondary infection after implantation, most of the patients with artificial penile nodules remain asymptomatic. ${ }^{24}$ As a rare complication the development of foreign body granulomas has been reported. ${ }^{4}$ In our case, the clinical features of the lesions, which were not typical for condylomata lata, were first interpreted as foreign body granuloma because two of the implanted spheres were directly situated under the diseased prepuce. Silica granuloma, ${ }^{7}$ carcinomalike sclerosing lipogranuloma ${ }^{8}$ and carcinoma of the penis were included in the differential diagnosis. Surprisingly the serological tests for syphilis were reactive, and together with the histological findings and clinical course a diagnosis of secondary syphilis was established. In short, our report illustrates the problems which may arise in the differential diagnosis of ulcerative genital lesions in the presence of artificial penile nodules.

Address correspondence to Dr P Wolf. 
1 Cohen EL, Kim SW. Subcutaneous artificial penile nodules. J Urol 1982;127:135.

2 Sundaravej K, Suchato C. Tancho's nodules. Australas Radiol $1974 ; 18: 453-4$.

3 Nitidandhaprabhas $P$. Artificial penile nodules: case reports from Thailand. Br J Urol 1975;47:463.

4 Gilmore WA, Weigand DA, Burgdorf WHC. Penile nodules in south-east Asian men. Arch Dermatol 1983;119:446-7.

5 Lim KB, Seow CS, Tan Tulip, Daniel M, Vijayasingham SM. Artificial penile nodules: case reports. Genitourin Med 1986;62:123-5.

6 Hovorka O. Verstümmelungen des männlichen Gliedes bei einigen Völkern des Altertums und der Jetztzeit, mit beson- derer Berücksichtigung der sogenannten Infibulation und Kynodesme. Mitteilungen der Anthropologischen Gesellschaft in Wien 1894;XXIV(XIV): 131-43.

7 Shelley WB, Hurley HJ. The pathogenesis of silica granuloma in man: A non-allergic colloidal phenomenon. J Invest Dermatol 1960;34:107-23.

8 Soyer HP, Petritsch P, Glavanovitz P, Kerl H. Sklerosierendes Lipogranulom (Paraffingranulom) des Penis unter dem klinischen Bilde eines Karzinoms. Hautarzt 1988;39:174-6.

Accepted for publication 14 March 1991 